\title{
POPULATION AND SELECTION STUDIES IN A TRITICUM CROSS
}

\author{
T. P. PALMER
}

Crop Research Division, Christchurch, New Zealand

Received 28.ix.5I

\section{INTRODUCTION}

YIELD increases are achieved in breeding programmes in two main ways, as pointed out by Frankel (1950); by removing or reducing the effects of factors which limit yield, which he called resistance breeding, or by direct selection for increases in yield itself, called production breeding. The present paper deals with some problems encountered in the second of these aspects of breeding.

The inheritance of yield, as of many other characters, is controlled by polygenic systems. The essential feature of such systems is that they are made up of many genes which have effects small in comparison with environmental variations, the individual polygenes occurring in more or less closely linked groups (Mather, 1942). Because environmental variations contribute more to the phenotype than any single polygene, superior polygenic combinations are often not observable in single plants or their immediate progenies, and in this way they contrast with oligogenes.

No character can be placed in either class unconditionally; oligogenes have polygenic modifiers, and, in some crosses, a group of closely linked polygenes might act as an oligogene. If genes interact with other genes or the environment, and gene action accordingly is not arithmetic, genetic changes observable at one level of expression may be unobservable at another. For example, where the environment limits development, increases in yield potential may not be observable.

Since genetic differences between plants are masked by environmental influences, selection of high yielding plants in the early generations after a cross is unlikely to be accurate. The chance of obtaining genetically superior plants from any population by phenotypic selection depends on their frequency, their relative phenotypic advantage, and the extent to which this advantage is genetically determined and fixable. The aim of the breeder is to produce and use populations from which the chance of successful selection is highest.

When breeding for increased yields of self-fertilised crops, two alternative methods-the bulk or mass method, and the pedigree methodare commonly used. Both methods, and modifications of them, have been adequately described (Harrington, I937; Akerman and MacKey, 1948). Briefly, with the pedigree method, single plant selection begins 
in $\mathrm{F}_{2}$ and is continued until progenies are considered to be homozygous for observable characters. When this stage is reached, usually after two or more generations of single plant selection, progenies of selected plants are tested. With the bulk method, single plant selection begins when the majority of plants is considered to be already homozygous, and is often confined to the one generation.

Various changes occur in bulked populations from $\mathrm{F}_{2}$ onwards. Two forces with predictable effects are acting; segregation and natural selection. The precise genetic effects of segregation depend on the number of genes segregating, their linkage and dominance relationships, and the magnitude and direction of gene interaction. Whatever the genetic situation, the general effects of segregation can be predicted.

The proportion of homozygotes in the population increases from $\mathrm{F}_{2}$ onwards according to the well known formula $\left[\frac{2^{r}-\mathrm{I}}{2^{r}}\right]^{n}$, where $r=$ the number of generations after $\mathrm{F}_{\mathrm{I}}$ and $n=$ the number of independently segregating genes. Linkage in effect reduces the number of segregating genes, and in either the coupling or repulsion phase increases the rate of attainment of homozygosis. The increase in the proportion of homozygotes, with the consequent elimination of heterozygotes, increases the phenotypic variance of the population. With arithmetic gene action, no dominance and no gene interaction, the variance when segregation has ceased is double that of $F_{2}$ (Wright, 1921). With some other genetic systems the increase in variance is not so great, but it occurs with all systems.

The effect of segregation on the population mean depends on the dominance relationships of the yield genes. If dominance is absent, the population mean remains unchanged from generation to generation. If dominance occurs, the mean in each succeeding generation approaches more closely to the mean of the parents of the cross as heterozygotes are eliminated.

Out crossing reduces the effects of segregation, but at a rate likely to be met with in most self-fertilised plants its effect on population structure is negligible. Bateman (195I) assuming $3 \%$ of outcrossing in each generation, states that this could greatly increase the heterozygosis of late generation plants. His assumption that natural selection favours heterozygotes must be generally invalid for self-fertilised plants. Ignoring any such effect, if 20 genes are segregating the proportion of complete homozygotes in $\mathrm{F} 8$ is reduced from $85 \%$ to $48 \%$ by $3 \%$ of out-crossing. But $84 \%$ of the population will be homozygous for 19 or more genes, with most of the remaining $16 \%$ homozygous for 18 genes.

Natural selection in seed crops generally favours those genotypes producing the greatest number of seeds, so, if seed weight and seed number are not inversely correlated, it favours the higher yielding genotypes. It thus tends to increase the population mean and to reduce its genetic variance. 
The effects of natural selection and segregation are revealed not only by the means and variances of $F_{2}$ and later generations but also by the parent-offspring correlations of $\mathrm{F}_{2}$ and later generation plants. If dominance occurs, progeny of heterozygotes tend to have lower mean yields than their parents, while progeny of homozygotes have the same yield as their parents. Consequently parent-offspring correlations of early generation plants, many of which are heterozygous, tend to be lower than those of late generation plants, which are mainly homozygotes. If no dominance exists, the mean yield of the progeny of heterozygous plants is the same as their parents, so that changes in the proportions of homozygotes and heterozygotes have no effect on the parent-offspring correlations. Natural selection reduces genetic variation, so that differences between late generation plants tend to be caused more by chance environmental factors than by genetic differences. If genetic variation is eliminated entirely, differences between plants are no longer inherited. Under these conditions parentoffspring correlations will be zero. We thus expect that natural selection tends to lower the parent-offspring correlations of late generation plants.

Natural selection and segregation thus act in opposite directions on the population variances. Where dominance occurs they act in opposite directions on the means and on the parent-offspring correlations. The effect of natural selection depends on the relative magnitudes of environmental and genetic variation, the constancy of the environment from generation to generation, and on the number of generations over which it acts. During the early generations segregation is the more potent force, but it is soon spent, later changes being caused by selection, which, as it reduces genetic variation, also ceases to cause further changes.

By the use of these statistics-population means, variances and parent-offspring correlations-the relative importance of natural selection and segregation can be assessed and the relative values of populations to the plant breeder estimated.

In the first part of this paper the $F_{2}$ and $F_{8}$ generations of a Triticum vulgare cross are so compared; in the second part the effects of selection in these two generations have been compared directly.

\section{MATERIAL AND METHODS}

The cross chosen for the study was Dreadnought $\times$ Cross 7 . Dreadnought is a wheat of English origin, and, compared with Cross 7, it has relatively larger grains and more grains per ear, but fewer ears and fewer grains per plant. Cross 7 was bred in New Zealand from Tuscan, a wheat of Mediterranean origin, and White Fife, an old Canadian wheat which originated in eastern Europe. The cross, as the parental and $F_{1}$ means show, presents scope for the combination of the higher yield components of both parents to give increased yield, or for the selection 
of transgressive segregates with values of yield and its components beyond the parental ranges.

The ancestors of the $F_{8}$ were 500 selected $F_{2}$ plants. As can be seen from table 7 , selection in $F_{2}$ may be, in fact, little better than random selection, so that it is considered that the selection of $5^{\circ 0}$ plants from the original $\mathrm{F}_{2}$ of about $\mathrm{r}$, ooo has had little effect on the bulk derived from them. From $F_{3}$ onwards the bulk was grown under normal ficld conditions, and each year the smaller grains-about one quarter to one third of the total-were sifted out before a sample was taken for sowing.

In 1945 the parents, $F_{1}, F_{2}$ and $F_{8}$ populations were grown. For all populations except the $F_{1}$ the plots consisted of two rows eight inches apart with $\mathrm{I}_{3}$ seeds four inches apart in each row. The $F_{1}$ plots, of which two were grown, consisted of only one row each. The whole material was sown in one block, each population occupying plots at random within the block. In the same block, also in random positions, were parental plots and progenies of plants selected in $F_{7}$ which were not used in this particular study. In 1946 the yield and yield components of ${ }_{1} 36$ Cross 7 plants from seven plots, i io Dreadnought plants from five plots, $25 \mathrm{~F}_{1}$ plants from two plots, ${ }^{8} 846 \mathrm{~F}_{2}$ plants from 88 plots and $1934 \mathrm{~F}_{8}$ plants from $9 \mathrm{I}$ plots, were determined.

The 75 highest yielding plants were selected from each of the $F_{2}$ and $F_{8}$ populations. Their progenies were sown in 1946 in two-row plots, rows eight inches apart, with 25 seeds two inches apart in each row. In addition, progenies of 50 randomly selected $F_{2}$ and $F_{8}$ plants were grown, together with $5^{\circ}$ Cross 7 and $48 \mathrm{~F}_{2}$ plots. Dreadnought was omitted because of its pronencss to shed grain. Sufficient seed was available for two replications. 'Total yield per plot and mean per plant values of yield components of the $\mathrm{F}_{3}$ and $\mathrm{F}_{9}$ plots were determined. In addition single plant values of yield and its components of some $\mathrm{F}_{3}$ and $\mathrm{F}_{9}$ plots were determined.

The following abbreviations are used:

$e=$ number of ears per plant, or mean number of ears per plant

$n=$ mean number of grains per ear

$g=$ mcan weight of one grain (milligrammes)

$e n=$ number of grains per plant, or mean number of grains per plant

$n g=$ mean weight of grain per ear (grammes)

eng $=$ weight of grain per plant, or mean weight of grain per plant (grammes)

$p=$ number of plants per plot

peng $=$ weight of grain per plot (grammes)

\section{A. Means}

\section{POPULATION STATISTICS}

The means of the parents and $\mathrm{F}_{1}$ are given in table $\mathrm{I}$. 
TABLE I

Means of parents and $F_{1}$

\begin{tabular}{|c|c|c|c|c|c|c|c|}
\hline & \multirow{2}{*}{ Cross 7} & \multirow{2}{*}{$\begin{array}{l}\text { Dread- } \\
\text { nought }\end{array}$} & \multirow{2}{*}{$\begin{array}{l}\text { Difference } \\
\text { Cross 7-- } \\
\text { Dreadnought }\end{array}$} & \multirow{2}{*}{$F_{i}^{i}$} & \multicolumn{2}{|c|}{$\begin{array}{c}\text { Difference } \\
F_{1}-\text { higher parent }\end{array}$} & \multirow{2}{*}{$p^{*}$} \\
\hline & & & & & absolute & $\because 0$ increase & \\
\hline$e$ & $4^{.04}$ & $3 \cdot 39$ & +0.65 & $4 \cdot 30$ & $+\cdot 26$ & $6 \cdot 4$ & 3 \\
\hline$n$ & $27 \cdot 9$ & $28 \cdot 3$ & -0.4 & $3 \mathrm{i} \cdot \mathrm{O}$ & $+2 \cdot 7$ & $9 \cdot 5$ & $\cdot 2-\cdot I$ \\
\hline$g$ & $5^{1} \cdot 9$ & $65^{\circ} \mathrm{O}$ & $-13 \cdot I^{* *}$ & 66.8 & $+\mathrm{r} \cdot 8$ & $2 \cdot 8$ & $.05-.02$ \\
\hline en & & IOI & $+1 I$ & 129 & +17 & $15 \cdot 2$ & 'I \\
\hline$n g$ & I. 44 & I.74 & $-0.30^{*}$ & $2 \cdot 00$ & +0.26 & 15.0 & -OI \\
\hline eng & $5 \cdot 86$ & $6 \cdot 6 \mathrm{I}$ & -0.75 & $8 \cdot 70$ & $+2 \cdot 09$ & $3 I^{1} \cdot 6$ & . OI \\
\hline
\end{tabular}

${ }^{*} p=$ probability that the mean of the higher parent $=$ the $F_{1}$ mean

Statistically significant differences between the parents occur for only two components, $g$ and $n g$, but the heterosis of all components in the $F_{1}$ shows that this phenotypic similarity masks a high degree of genetic diversity.

TABLE 2

Means of $F_{2}$ and $F_{8}$

\begin{tabular}{|c|c|c|c|c|c|}
\hline & \multicolumn{2}{|c|}{$F_{2}$} & \multicolumn{2}{|c|}{$F_{8}$} & \multirow{2}{*}{$\begin{array}{c}\text { Difference } \\
F_{8}-F_{2}\end{array}$} \\
\hline & Calculated ${ }^{+}$ & observed & Calculated $^{++}$ & observed & \\
\hline$e$ & $4^{\circ} \cdot 01 \pm I: 99$ & $3 \cdot 80$ & $3 \cdot 7^{2} \pm \cdot 9 I$ & $3 \cdot 83$ & +0.03 \\
\hline$n$ & $29.6 \pm 3.9$ & $27 \cdot 3$ & $28 \cdot 1 \pm 4 \cdot 2$ & $28 \cdot 5$ & $+\mathrm{I} \cdot 2^{* *}$ \\
\hline$g$ & $62 \cdot 6 \pm 3 \cdot 4$ & $5^{8 \cdot 9}$ & $58 \cdot 5 \pm 2 \cdot 7$ & $5^{6 \cdot 9}$ & $-2 \cdot 0 * *$ \\
\hline en & $118 \pm 24$ & 104 & $107 \pm 34$ & Iog & $+5^{* *}$ \\
\hline$n g$ & $I \cdot 80 \pm \cdot 24$ & $\mathrm{I} \cdot 62$ & $I \cdot 59 \pm \cdot 2 I$ & $I \cdot 64$ & $+0.02^{* *}$ \\
\hline eng & $7 \cdot 47 \pm 1 \cdot 55$ & $6 \cdot 16$ & $6 \cdot 24 \pm 1 \cdot 93$ & $6 \cdot 19$ & +0.03 \\
\hline $\begin{array}{r}p \\
\text { peng }\end{array}$ & & $\begin{array}{l}21 \cdot 99 \\
136\end{array}$ & & $\begin{array}{l}21 \cdot 30 \\
132\end{array}$ & $\begin{array}{l}-0.69^{* *} \\
-4 \cdot 00\end{array}$ \\
\hline & & & & & \\
\hline
\end{tabular}

$+\mathrm{F}_{2}$ calculated $=\mathrm{I} / 4\left(\mathrm{P}_{1}+\mathrm{P}_{2}+2 \mathrm{~F}_{1}\right)$

$++F_{8}$ calculated $=1 / 256\left(127 \ddot{P}_{1}+127 P_{2}+2 F_{1}\right)$

** Significant at $\mathrm{I}$, , i, level

The observed $\mathrm{F}_{2}$ means (table 2) are consistently lower than the expected $\mathrm{F}_{2}$ means as calculated from the parents and $\mathrm{F}_{1}$, but none of the deviations is significant, so that the direct scales of measurement used give adequate estimates of the population means (Mather, I949). This is confirmed by the absence of correlation between means and variances ( $c f$. tables 2 and 3 ).

In a cross showing dominance, if no effective selection occurs, the mean in each generation after $\mathrm{F}_{2}$ approaches more closely to the midparent mean, the $\mathrm{F}_{8}$ and mid-parent mean being almost identical.

In this material, the $\mathrm{F}_{2}$ means of all characters were already close to the mid-parent, so that segregation in succeeding generations would have had little effect on the $\mathrm{F}_{8}$ population means. Differences between $\mathrm{F}_{2}$ and $\mathrm{F}_{8}$ must then be due to selection. 
$p$. The $\mathrm{F}_{2}$ mean of $p$ is significantly higher than the $\mathrm{F}_{8}$ mean. Engledow and $\mathrm{Pal}$ (1934) have reported higher germination in early generations of wheat crosses, while Copeland (1940) has reported higher growth rates of embryos in hybrid than in inbred corn. Some similar effect may account for the high $p$ in the $\mathrm{F}_{2}$ of this cross.

$e, n$ and $e n$. The mean of $e$ is similar in both populations; $n$ and $e n$ are higher in $F_{8}$ than in $F_{2}$. The number of immediate offspring of any plant is determined by $e n$. The main determinant of $e n$ is $e$ (for $e$ and $e n, r=+0.93^{* *}$; for $n$ and $e r, r=+\cdot 03^{* *}$ in the $\mathrm{F}_{2}$ population), but $e$ is much more subject to environmental variation than $n$ (see coefficients of variability below). This explains why natural selection had little effect on $e$, but significantly increased $n$ and $e n$.

\section{Coefficients of variability}

\begin{tabular}{|c|c|c|c|c|c|c|c|}
\hline & & $e$ & $n$ & $g$ & $e n$ & $n g$ & eng \\
\hline 7 & & 28 & 20 & 8 & 43 & 23 & \\
\hline Dreadnought & 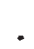 & 46 & 22 & 5 & 48 & 15 & \\
\hline
\end{tabular}

g. The smaller grains were sifted out before sowing. In other Triticum vulgare crosses, Copp (unpublished) has shown that mass selection for large grains, as practised in this material, was effective in increasing the mean of $g$ in the succeeding generation. In this material, however, such selection, if at all effective, merely counteracted the effects of natural selection, for $g$ and $e n$ are negatively correlated $\left(r=-0.24^{* *}\right.$ in the $\mathrm{F}_{8}$, and $r=-0.35^{* *}$ in the $\left.\mathrm{F}_{2}\right)$. Natural selection for $e n$ therefore resulted in reduced $g$. Had selection for $g$ not been practised, the $\mathrm{F}_{8}$ mean of $g$ might have been still lower.

eng. The decrease in $g$ is compensated by the increase in $e n$ so that the mean of eng is the same in both the $\mathrm{F}_{2}$ and $\mathrm{F}_{8}$.

peng. The lower value of peng in $F_{8}$ is caused by the lower value of $p$ in that population.

To sum up, natural selection for en adequately accounts for the changes in the population means between $F_{2}$ and $F_{8}$. Had these changes been caused by the selection for eng in the $F_{2}$ from which the $\mathrm{F}_{8}$ derived, eng itself would be higher than in this unselected $\mathrm{F}_{2}$ (see page I 74).

B. Variances

TABLE 3

Variances of parents, $F_{1}, F_{2}$ and $F_{8}$

\begin{tabular}{|c|c|c|c|c|c|}
\hline & Cross 7 & Dreadnought & $\mathrm{F}_{1}$ & $\mathrm{~F}_{2}$ & $\mathrm{~F}_{8}$ \\
\hline$e$ & $1 \cdot 30$ & $2 \cdot 00$ & $\cdot 76$ & $\mathrm{1} \cdot 93$ & $\mathrm{r} \cdot 65$ \\
$n$ & 32 & 38 & 42 & 35 & 32 \\
$g$ & $\mathrm{I8}$ & $\mathrm{rI}$ & 40 & 60 & 44 \\
$e n$ & 2258 & 2319 & 1067 & 2059 & 2117 \\
$n g$ & $\cdot 1 \mathrm{I}$ & $\cdot 07$ & $\cdot 18$ & 16 & $\cdot 14$ \\
$e n g$ & $6 \cdot 60$ & $8 \cdot 28$ & $5 \cdot 84$ & $7 \cdot 73$ & $6 \cdot 20$ \\
\hline
\end{tabular}


TABLE 4

Variance ratios of parents, $F_{2}$ and $F_{8}$

\begin{tabular}{|c|c|c|c|c|c|c|}
\hline & $\begin{array}{l}\text { Dreadnought } \\
\text { cf. Cross } 7\end{array}$ & $\begin{array}{l}\text { Dreadnought } \\
\text { cf. } F_{2}\end{array}$ & $\begin{array}{l}\text { Cross } 7 \\
\text { cf. } F_{2}\end{array}$ & $\underset{\text { cf. } F_{8}}{F_{2}}$ & $\begin{array}{l}\text { Dr. } \\
\text { cf. } \dot{F}_{8}\end{array}$ & $\begin{array}{l}\text { Cr. } 7 \\
\text { cf. } F_{8}\end{array}$ \\
\hline $\begin{array}{r}e \\
n \\
g \\
e n \\
n g \\
e n g\end{array}$ & $\begin{array}{l}1 \cdot 54^{*} \\
1.19 \\
1.64^{* *} \\
1.03 \\
1.65^{* *} \\
1 \cdot 25\end{array}$ & $\begin{array}{l}1 \cdot 04 \\
1 \cdot 08 \\
5 \cdot 28^{* *} \\
1 \cdot 13 \\
2 \cdot 45^{*} \\
1 \cdot 07\end{array}$ & $\begin{array}{l}\mathbf{1} \cdot 4^{8 * *} \\
\mathbf{1} \cdot 12 \\
3 \cdot 35^{* *} \\
1 \cdot 10 \\
1 \cdot 49^{* *} \\
1 \cdot 17\end{array}$ & $\begin{array}{l}1 \cdot 17^{* *} \\
1 \cdot 09^{* *} \\
1 \cdot 36^{* *} \\
1 \cdot 03 \\
1 \cdot 14^{* *} \\
1 \cdot 24^{* *}\end{array}$ & $\begin{array}{l}1 \cdot 21^{*} \\
1 \cdot 19 \\
4 \cdot 00^{* *} \\
1 \cdot 10 \\
2 \cdot 00^{* *} \\
1 \cdot 34^{*}\end{array}$ & $\begin{array}{l}\text { I.22* } \\
1 \cdot 00 \\
2 \cdot 44^{* *} \\
1 \cdot 07 \\
1 \cdot 27^{*} \\
1 \cdot 06\end{array}$ \\
\hline
\end{tabular}

* significant at $10 \%$ level

** significant at $2 \%$ level

\section{Parents and $F_{2}$}

In self-fertilised plants the parents and the $F_{1}$ generation of crosses are usually considered to be genetically uniform, and are therefore used to estimate the environmental variation present in the experimental area. In fact, the parents may not be devoid of genetic variation, but the ratio of environmental to genetic variance will be much higher in the parents than the $F_{2}$. We therefore expect a higher total variance in the $F_{2}$ than in the parents and $F_{1}$, and that the variances of the two parents will be similar.

The $\mathrm{F}_{2}$ variances of all components except $e n$ are higher than the Cross 7 variances, variances of $e, g$ and $n g$ being significantly so (tables 3 and 4). Comparing the $\mathrm{F}_{2}$ with Dreadnought, however, only $g$ and $n g$ have lower variances in the Dreadnought population, though no Dreadnought variances are significantly higher than $\mathrm{F}_{2}$ variances. In addition, the Cross 7 and Dreadnought variances of $e, g$ and $n g$ are significantly different. It is therefore unlikely that the parental variances give a true indication of the ratio of environmental to genetic variances in the segregating populations; obviously there are here interactions between genotype and environment.* Re-scaling could equalise the parental variances, but the other criteria for an adequate scale (see above) would not then be satisfied.

The populations used to estimate the parental variances were small, but the inter-plot variances of those parent plots analysed plant-wise were, except in the case of $e$ in Dreadnought, lower than the inter-plant variances of all Dreadnought and Cross 7 plots grown in the experimental area. Apparently the variation of the parents was not over-estimated in the small samples taken.

$F_{2}$ and $F_{8}$. The $\mathrm{F}_{8}$ variances of all components except $e n$ are significantly lower than those of $F_{2}$. As has been shown before, segregation increases population variances, selection tends to decrease them. Here, as with the means, the effects of selection outweigh the effects of segregation.

* Similarly high parental variances have been reported by Hutchinson, Panse and Govande (1938). 


\section{Frequency Distribution}

The reduction in variances between $F_{2}$ and $F_{8}$ may be the result of selective elimination of genotypes at either or both ends of the range. As many of the frequency distributions are not normal, elimination of genotypes from the upper end of the range may have occurred even for those components with a higher $\mathrm{F}_{8}$ mean. This would reduce the chances of selecting high values. Table 5 compares the percentages of the $\mathrm{F}_{2}$ and $\mathrm{F}_{8}$ populations falling above limits set to exclude roughly the top $5 \%$ of the population for each character.

TABLE 5

Percentages of $F_{2}$ and $F_{8}$ above arbitrary limits

\begin{tabular}{|c|c|c|c|c|c|c|c|}
\hline & \multirow[b]{2}{*}{ above } & \multirow[b]{2}{*}{$F_{2}$} & \multirow[b]{2}{*}{$\mathrm{F}_{8}$} & \multirow[b]{2}{*}{$X^{2}$} & \multirow[b]{2}{*}{$p$} & \multicolumn{2}{|c|}{ No. of Plants } \\
\hline & & & & & & $F_{2}$ & $\mathrm{~F}_{8}$ \\
\hline$e$ & 5 & $7 \cdot 44$ & $7 \cdot 83$ & $\cdot 2 I$ & $<\cdot 70$ & I 866 & 1942 \\
\hline$n$ & 37 & $5 \cdot 3 x$ & $6 \cdot 88$ & 4.02 & $<\cdot 05$ & $x 846$ & I 934 \\
\hline$g$ & $6 \cdot 70$ & $10 \cdot 08$ & $5 \cdot 17$ & $29 \cdot 33$ & $<.01$ & $"$ & , \\
\hline$e n$ & I 90 & 4.01 & 4.65 & .99 & $<40$ & ", & " \\
\hline$n g$ & $2 \cdot 20$ & $5 \cdot 74$ & 5.69 & - & -80 & , & " \\
\hline eng & $10 \cdot 90$ & $5 \cdot 20$ & $5 \cdot 3^{8}$ & $\cdot 08$ & $<\cdot 80$ & , & , \\
\hline
\end{tabular}

There were relatively more $\mathrm{F}_{8}$ plants in the top fraction for $n$, and less for $g$. No significant changes had occurred for $e$ and $e n$. Of the plants outside the upper limit for $g$, only 20 of the $F_{2}$ and 10 of the $F_{8}$ had eng higher than 10.90 grammes. Of the plants with en above 190, 73 of the $\mathrm{F}_{8}$ and 64 of the $\mathrm{F}_{2}$ had yield higher than 10.90. These proportions, together with the cffect of selection for eng (table 6), show that high en is the main cause of high eng. The non-significant upward change in $e n$ has counter-balanced the much larger drop in $g$, so that the proportion of individuals with high values of eng remains the same in both populations.

\section{SELECTION FOR YIELD}

The 75 highest yielding plants were selected from $F_{2}$ and $F_{8}$.

TABLE 6

Differences between selected and unselected $F_{2}$ and $F_{8}$

\begin{tabular}{|c|c|c|c|c|}
\hline & \multicolumn{2}{|c|}{$\begin{array}{c}\mathrm{F}_{2} \\
\text { Difference } \\
\text { Selected - Unselected }\end{array}$} & \multicolumn{2}{|c|}{$\begin{array}{c}\mathrm{F}_{8} \\
\text { Differencc } \\
\text { Selected - Unselected }\end{array}$} \\
\hline & absolute & $\%$ increasc & absolute & $\%$ increase \\
\hline $\begin{array}{r}e \\
n \\
g \\
e n \\
n g \\
e n g\end{array}$ & $\begin{array}{c}2 \cdot 07^{* *} \\
6 \cdot 5^{* *} \\
3 \cdot 6^{* *} \\
98^{* *} \\
46^{* *} \\
5 \cdot 96^{* *}\end{array}$ & $\begin{array}{r}49 \\
23 \\
6 \\
83 \\
27 \\
82\end{array}$ & $\begin{array}{c}2 \cdot 26^{* *} \\
4 \cdot 4^{* *} \\
2 \cdot 3^{* *} \\
95^{* *} \\
-35^{* *} \\
6 \cdot 09^{* *}\end{array}$ & $\begin{array}{r}54 \\
14 \\
4 \\
74 \\
20 \\
85\end{array}$ \\
\hline
\end{tabular}


In the selected fractions of both $\mathrm{F}_{2}$ and $\mathrm{F}_{8}$, the means of all yield components were increased (table 6). Of the primary components, $e, n$ and $g$, the percentage increase was greatest in $e$ and least in $g$. Thus selection for eng was in effect mainly selection for $e$, the component most affected by environmental variation.

There are two obvious ways in which to judge the effectiveness of selection in the two populations:

I. By a comparison of the parent-offspring correlations, or of the differences between progeny means of selected and unselected plants in each population.

2. By a comparison of the progeny means of plants selected from the two populations.

The first method shows in which population the greater change will be achieved, but does not necessarily show from which population the higher yielding lines will be obtained. It measures the genetic variability of the populations, but disregards their means. The second method fails to show the potentialities for further selective increases, or indeed, whether any advances will be obtained by selection.

TABLE 7

Average plot means of yield and yield components

\begin{tabular}{|c|c|c|c|c|c|c|c|c|}
\hline & $\begin{array}{c}\text { Cross } \\
7\end{array}$ & $\mathrm{~F}_{2}$ & $\begin{array}{c}\mathrm{F}_{3} \text { from } \\
\text { unselected } \\
\mathrm{F}_{2}\end{array}$ & $\begin{array}{c}\mathrm{F}_{3} \text { from } \mathrm{F}_{2} \\
\text { selected } \\
\text { for yield }\end{array}$ & $\begin{array}{l}\text { Selected } \\
\text { minus } \\
\text { unselected }\end{array}$ & $\begin{array}{c}F_{9} \text { from } \\
\text { unselected } \\
F_{8}\end{array}$ & $\begin{array}{c}\mathrm{F}_{8} \text { from } \mathrm{F}_{8} \\
\text { selected } \\
\text { for yield }\end{array}$ & $\begin{array}{l}\text { selected } \\
\text { minus } \\
\text { unselected }\end{array}$ \\
\hline$e$ & $3 \cdot 14$ & $3 \cdot 18$ & $2 \cdot 97$ & $3 \cdot 13$ & $+\cdot 16$ & 3.04 & 3.02 & -.02 \\
\hline$n$ & 28 & 30 & 30.15 & 28.88 & -1.27 & $30 \cdot 04$ & $30 \cdot 24$ & +20 \\
\hline$g$ & $40 \cdot 3$ & $5^{2 \cdot 6}$ & $48 \cdot 6$ & $49 \cdot 5$ & $+\cdot 9$ & $47 \cdot 7$ & $48 \cdot 6$ & $+\cdot 9$ \\
\hline en & 90 & 94 & $88 \cdot 5^{8}$ & $88 \cdot 97$ & $+\cdot 39$ & 91.66 & $90 \cdot 80$ & -.26 \\
\hline$n g$ & $I \cdot 17$ & I. 54 & $I \cdot 46$ & $I \cdot 4 \mathrm{I}$ & -.05 & $\mathrm{I} \cdot 4^{\mathrm{I}}$ & I. 45 & $+\cdot 04$ \\
\hline eng & $3 \cdot 67$ & $4 \cdot 90$ & $4 \cdot 30$ & $4 \cdot 3^{8}$ & +.08 & $4 \cdot 29$ & $4 \cdot 37$ & $+\cdot 08$ \\
\hline$p$ & 26 & 38 & 33 & 36 & +3.0 & 33 & 35 & $+2 \cdot 0$ \\
\hline peng & $9^{2}$ & 184 & I 42 & I $5^{8}$ & $+16^{* *}$ & I 39 & I 53 & $+14^{* *}$ \\
\hline
\end{tabular}

The means of the $F_{3}$ and $F_{9}$ plots were essentially similar (see table 7), so the populations can be compared by the first method.

Selection for eng failed to increase eng significantly in the succeeding generation. The only significant change was an increase in peng in the progenies of selected plants. This increase is due partly to the small non-significant increase in eng, but mainly to the increase in $p$. Selection for eng was equally ineffective in either population. The parentoffspring correlation of eng in the random selections from $\mathrm{F}_{2}$ is significant, that of the $F_{8}$ is not. Judged on this count, selection in $F_{2}$ has been slightly more effective than selection in $\mathrm{F}_{8}$.

Selection for yield in both populations has been a comparative failure. Selection may have been ineffective because environmental variation was high in the $\mathrm{F}_{2}$ and $\mathrm{F}_{8}$ populations, or conversely, because genetic variation was low in these populations, though this could hardly 
TABLE 8

Rep I - Rep 2 and offspring-parent correlation coefficients

\begin{tabular}{|c|c|c|c|c|c|c|}
\hline & & & $\begin{array}{c}F_{9} \text { from } \\
\text { unselected } F_{8}\end{array}$ & $\begin{array}{c}F_{9} \text { from } \\
\text { selected } F_{8}\end{array}$ & $\begin{array}{c}\mathrm{F}_{3} \text { from } \\
\text { unselected } F_{2}\end{array}$ & $\begin{array}{c}\mathrm{F}_{3} \text { from } \\
\text { selected } F_{2}\end{array}$ \\
\hline$e$ & $\begin{array}{l}\text { rep } 1-\text { rep } 2 \\
\text { parent offspring }\end{array}$ & $\cdot$ & $\begin{array}{r}\cdot 06 \\
-\cdot 06\end{array}$ & $\begin{array}{l}\cdot 18 \\
\cdot 16\end{array}$ & $\begin{array}{r}\cdot 14 \\
-\cdot 13\end{array}$ & $\begin{array}{l}\cdot 22 \\
\cdot 14\end{array}$ \\
\hline$n$ & $\begin{array}{l}\text { rep } 1-\text { rep } 2 \\
\text { parent offspring }\end{array}$ & . & $\begin{array}{l}\cdot 36^{* *} \\
\cdot 15\end{array}$ & $\begin{array}{l}\cdot 32^{* *} \\
\cdot 23^{*}\end{array}$ & $\begin{array}{l}\cdot 22 \\
\cdot 21\end{array}$ & $\begin{array}{l}\cdot 24^{*} \\
\cdot 27^{*}\end{array}$ \\
\hline$g$ & $\begin{array}{l}\text { rep } 1 \text { - rep } 2 \\
\text { parent offspring }\end{array}$ & • & $\begin{array}{l}\cdot 79^{* *} \\
\cdot 76^{* *}\end{array}$ & $\begin{array}{l}\cdot 70^{* *} \\
\cdot 73^{* *}\end{array}$ & $\begin{array}{l}\cdot 66^{* *} \\
\cdot 73^{*}\end{array}$ & $\left.\begin{array}{l}\cdot 83^{* *} \\
\cdot 68^{* * *}\end{array}\right\}^{+}$ \\
\hline en & $\begin{array}{l}\text { rep } 1-\text { rep } 2 \\
\text { parent offspring }\end{array}$ & . & $\left.\begin{array}{r}\cdot 2 I \\
-\cdot 26\end{array}\right\}^{+}$ & $\begin{array}{l}\cdot 21 \\
\cdot 14\end{array}$ & $\begin{array}{r}-\cdot 07 \\
\cdot 04\end{array}$ & $\begin{array}{l}\cdot 20 \\
\cdot 11\end{array}$ \\
\hline$n g$ & $\begin{array}{l}\text { rep } 1 \text { - rep } 2 \\
\text { parent offspring }\end{array}$ & • & $\begin{array}{l}\cdot 50^{* * *} \\
\cdot 22\end{array}$ & $\begin{array}{l}\cdot 52^{* *} \\
\cdot 33^{* *}\end{array}$ & $\begin{array}{l}\cdot 17 \\
\cdot 37^{* *}\end{array}$ & $\begin{array}{l}\cdot 22 \\
\cdot 07\end{array}$ \\
\hline eng & $\begin{array}{l}\text { rep I - rep } 2 \\
\text { parent offspring }\end{array}$ & • & $\begin{array}{l}\cdot 3 I^{*} \\
-\cdot 12\end{array}$ & $\begin{array}{l}\cdot 28 * \\
\cdot 07\end{array}$ & $\begin{array}{r}-.09 \\
.27^{*}\end{array}$ & $\begin{array}{r}\cdot 18 \\
-\cdot 02\end{array}$ \\
\hline
\end{tabular}

** correlation coefficient significant at $5 \%$

\}$^{+*}$ significantly different pairs of correlation coefficients $5 \%$

be so for the $\mathrm{F}_{2}$. It may have failed because environmental variation per se in $\mathrm{F}_{3}$ and $\mathrm{F}_{9}$ was high.

TABLE 9

Variances of plot means of $F_{3}, F_{9}$ and Cross 7

\begin{tabular}{|c|c|c|c|c|c|}
\hline & $\begin{array}{c}\mathbf{F}_{3} \\
\text { Unselectcd }\end{array}$ & $\begin{array}{c}\mathbf{F}_{9} \\
\text { Unselected }\end{array}$ & $\begin{array}{c}\mathbf{F}_{3} \text { from } \\
\text { selected } \mathbf{F}_{2}\end{array}$ & $\begin{array}{c}\mathbf{F}_{9} \text { from } \\
\text { selected } \mathbf{F}_{8}\end{array}$ & Cross 7 \\
\hline$e$ & $\cdot 23$ & 30 & $\cdot 28$ & $\cdot 31$ & $\cdot 25$ \\
$n$ & 22 & 32 & 35 & 28 & 22 \\
$g$ & $2 \cdot 4$ & $2 \cdot 8$ & $3 \cdot 0$ & $2 \cdot 9$ & $1 \cdot 0$ \\
$e n$ & 320 & 549 & 537 & 554 & 494 \\
$n g$ & $\cdot 054$ & $\cdot 083$ & $\cdot 073$ & $\cdot 067$ & .033 \\
$e n g$ & $\cdot 90$ & $1 \cdot 16$ & $1 \cdot 23$ & $1 \cdot 27$ & .66 \\
\hline
\end{tabular}

We have shown that the genetic variability of the $F_{8}$ is lower than that of $\mathrm{F}_{2}$. However, if genetic variability of the $\mathrm{F}_{8}$ population has been reduced to such an extent that further progress by selection is impossible, the variances of the $F_{9}$ means should be lower than the variances of the $\mathrm{F}_{3}$ means, and perhaps similar to Cross 7 . In fact they are not, though the variances of the random $F_{3}$ plots are unaccountably low (table 9). Presumably, then, lack of genetic variability in the $F_{2}$ and $F_{8}$ populations is not the cause of the failure of selection.

The relatively high environmental variation among $F_{2}$ and $F_{8}$ plants must have contributed to the failure of selection, especially as selection 
was based mainly on $e$, the primary component most affected by environmental variation. However, we cannot ascribe all the failure to this alone. Correlations between progeny means in the two replications were also relatively low, and seldom significantly different from the parent-offspring correlations (table 8), indicating that environmental variations between $F_{3}$ and $F_{9}$ plots were considerable.

TABLE 10

Mean intra-plot variances of $F_{3}$ and $F_{9}$

\begin{tabular}{|c|c|c|c|c|}
\hline & $F_{3}$ & $F_{9}$ & $F_{3}-F_{9}$ & $p^{*}$ \\
\hline $\left.\begin{array}{c}\text { number of } \\
\text { plots }\end{array}\right\}$ & 49 & $5^{\circ}$ & & \\
\hline$e$ & $1 \cdot 58$ & $1 \cdot 48$ & . 10 & $\cdot 3$ \\
\hline$n$ & $8 \mathrm{I}$ & 71 & II & $\cdot 2$ \\
\hline & 37 & 22 & 15 & $\cdot O I$ \\
\hline$e n$ & 2910 & 2720 & 190 & $\cdot 4$ \\
\hline$n g$ & $\cdot 22$ & $\cdot 17$ & .05 & $\cdot O I$ \\
\hline eng & $7 \cdot 21$ & $6 \cdot 12$ & I.09 & $\cdot 05$ \\
\hline
\end{tabular}

$p^{*}=$ probability that $\mathbf{F}_{3}=\mathrm{F}_{8}$

For $g, n g$ and eng $F_{3}$ intra-plot variances are higher than $F_{9}$ intraplot variances (table Io). For these characters at least, $F_{2}$ plants are more heterozygous than $\mathrm{F}_{8}$ plants. The heterozygosity of $\mathrm{F}_{2}$ plants will lower the $\mathrm{F}_{2}-\mathrm{F}_{3}$ correlations only if dominance effects are present in the $\mathrm{F}_{2}$. This $\mathrm{F}_{2}$ showed little if any dominance, so that, even though $\mathrm{F}_{2}$ plants were heterozygous, this would have had little effect on the $\mathrm{F}_{2}-\mathrm{F}_{3}$ correlations.

One significant effect, an increase in peng, resulted from selection for eng. This increase is mainly the result of an increase in $p$. The high mortality in the $\mathrm{F}_{3}$ and $\mathrm{F}_{9}$ plots was caused by foot-rot. As most of the deaths occurred in the later stages of development, plants adjacent to gaps did not benefit. Consequently, plot means of eng were not affected (correlation of $p$ and $e n g=-0.05$ ). The progeny of those plants with the greatest number of ears suffered least deaths, the correlation of parental $e$ with progeny $p$ being $+0.32^{* *}$ in both the populations. This correlation is higher than the parent-offspring correlation of $e$. This suggests that those $\mathrm{F}_{2}$ and $\mathrm{F}_{8}$ plants with a large $e$ possessed some quality, perhaps freedom from seed-borne foot-rot, which enhanced the survival rate of their progeny.

As high environmental variation has been the main cause of the failure of selection, selection for a less variable component, notably $g$, should have been more effective than selection for eng. Progenies of high yielding and unselected $\mathrm{F}_{2}$ and $\mathrm{F}_{8}$ plants with high values (top $10 \%$ ) of the individual components are compared with the whole of each population in table II.

Although some progress was achieved by selection for other components, $g$ was the only one which was consistently and significantly 
increased. The parent-offspring correlations for the various components show essentially the same result. That for $g$ is the only one which is high and consistently significant. However, $g$ and $e n$ were negatively correlated in the $\mathrm{F}_{3}$ and $\mathrm{F}_{9}$ populations $\left(r=-\mathrm{O}_{\mathbf{I}} \mathrm{I}\right.$ and $r=-0.25$ respectively), and the increase in $g$ did not increase $e n g$.

TABLE II

Advances made by selection for components

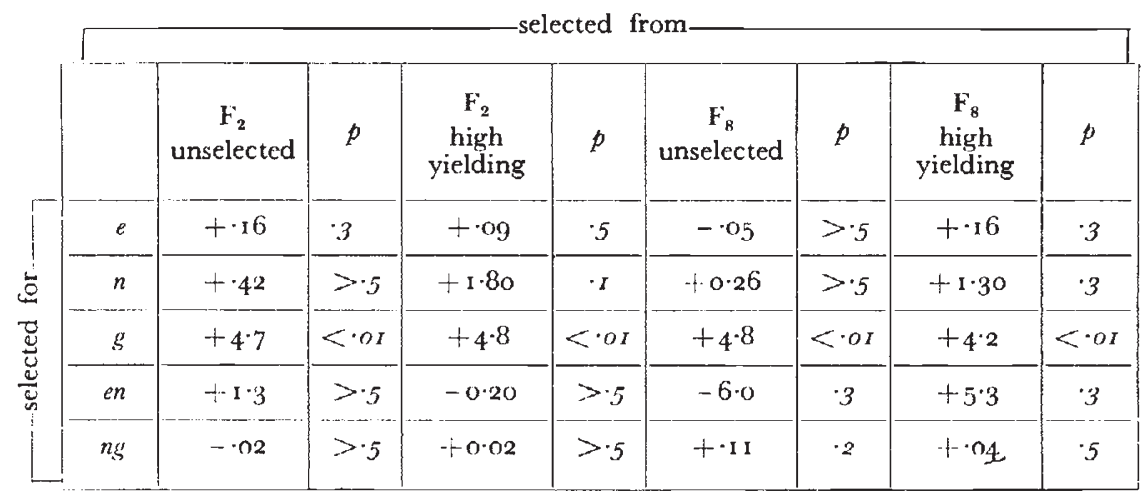

$p=$ probability that this difference $=0$

\section{DISCUSSION}

The evidence presented in the first part of this paper shows that natural selection has been the main force moulding the constitution of the hybrid bulk. In general, natural selection in seed crops favours the higher yielding genotypes (Harlan and Martini, I938; Laude and Swanson, r 942; for further references see Haldane, r932). However, the number, rather than the weight, of seeds produced per plant determines which genotypes have the greatest selective value. Where seed weight and seed number are inversely correlated, natural selection may favour lower yielding genotypes. Such a relationship exists in this matcrial and accounts for the relative smallness of the yield increase between $F_{2}$ and $F_{8}$. Suneson (1949) found that in a mixture of four barley varieties grown for 16 years, the highest yielding genotype was eliminated. He concluded that this was due to the lower competitive ability of the higher yielding variety. Differences in survival rate may have been determined by differences in seed numbers and grain weight, but unfortunately no data on these attributes of the four varieties were given.

In special circumstances, such as those described by Weiss et al. (I947) in soya bean where the interaction between seasonal differences and variations in maturity dates was the main determinant of yield variation, natural selection may not eliminate low yielding genotypes.

The similarity of the $\mathrm{F}_{2}, \mathrm{~F}_{8}$ and parental variances, and the low correlations between replications show that environmental variation among single plants and their progenies was high in relation to genetic 
variation. Consequently selection for eng was ineffective in both the $\mathrm{F}_{2}$ and $\mathrm{F}_{8}$ populations. In this material, where dominance effects were virtually absent in $\mathrm{F}_{2}$, the heterozygosity of $\mathrm{F}_{2}$ plants had little effect on the effectiveness of selection.

We can fairly say that in these circumstances yield and some yield components behave as unobservable characters, selection based on them being little better than random selection. One component, $g$, could be reliably selected for in single plants. However, as $g$ and $e n$ were negatively correlated, this was of no help in selecting for yield, but suggests that random selection in the early stages of a selection programme may be a safer procedure than selection for relatively unimportant observable characters, which may be adversely linked with yield itself.

Is single plant selection usually as ineffective as it has been in this case? Too few examples have been reported to permit any general conclusions as to its effectiveness. However, these results, and those of some other workers (Christian and Gray, r94I ; Panse, I940; Boyce, Copp and Frankel, I947) show that it is not universally successful. Selection indices attaching greatest weight to those components with the least environmental variance have been proposed as an improvement (Smith, I936). Panse (1947) found that these "discriminant functions did not appear to be much superior to straightforward selection on the character itself".

No great difficulty is involved in incorporating tests of effectiveness of selection in a breeding programme. Either bulk plots of the unselected material or random selections will serve as reasonable standards of comparison (cf. Hutchison et al., I938). If no progress is being made in selection for yield in the early generations of selection, random selection will be preferable to selection based on unimportant ancillary characters.

It might be inferred that a more rigid control of the environment would greatly improve the position. This would increase the effectiveness of selection in any particular environment. However, because the products of selection are grown in a diversity of ever changing environments, rigid control, while increasing the apparent effectiveness of selection, would limit its usefulness.

The present case gives no clear-cut evidence in favour of either the pedigree or bulk method of breeding. However, the increase in the proportion of homozygous plants and the increase in the population mean as a result of natural selection increased the potential worth of the $F_{8}$ population. In general, we can expect any changes in the bulked populations to be to the breeders' advantage. The increase in homozygosis confers certain practical advantages in the later stages of selection. The number of generations of single plant selection can be reduced, and the final purification of lines is simplified by the absence of unwanted segregates.

In addition, the bulk method permits selection between crosses 
before selection within crosses commences. Inferior crosses can be detected with some degree of precision in bulked yield trials in the $\mathrm{F}_{2}$ and later generations (Immer, I94 I Harrington, I940). Consequently, using the bulk method more crosses can be carried, and more plants selected from each cross. The chances of successful selection are therefore enhanced.

Some breeders fear that when using the bulk method they may lose desirable genotypes which would have been preserved by selection in $\mathrm{F}_{2}$. Akerman and MacKey (1948) discuss this problem, and point out that if the $\mathrm{F}_{2}$ used to perpetuate the bulk is of sufficient size, such fears are groundless.

It would appear that where only a few genes of importance are segregating, or where speed is essential, the pedigree method is preferable. Where many genes are segregating, or where selection for recessive oligogenes is combined with polygenic selection, the bulked population method makes more economical use of the available facilities, while possibly enhancing the prospects of success.

\section{SUMMARY}

I. In the wheat cross Dreadnought $\times$ Cross 7 , a comparison was made between parents, $F_{1}, F_{2}$ and $F_{8}$ to determine the changes in yield and yield components which occurred between $F_{2}$ and $F_{8}$, and to determine the factors responsible for these changes. Means, variances and frequency distributions were compared, and also the parent-offspring correlations of $\mathrm{F}_{2}-\mathrm{F}_{3}$ and $\mathrm{F}_{8}-\mathrm{F}_{9}$.

2. Natural selection for high number of grains per plant increased both the number of grains per plant and number of grains per ear. Since the number of grains per plant was inversely correlated with grain weight, the grain weight was reduced.

3. The variances of all components except number of grains per plant decreased between $F_{2}$ and $F_{8}$. These changes were also the result of natural selection.

4. Except for grain weight, parent-offspring correlations were low and generally non-significant. No consistent differences were observed between $\mathrm{F}_{2}-\mathrm{F}_{3}$ and $\mathrm{F}_{8}-\mathrm{F}_{9}$ correlations.

5. Selection for grain weight was successful; selection for yield or the other yield components was not.

6. The relevance of these findings to general plant breeding is discussed.

\section{REFERENCES}

AKERMAN, A., AND MACKEY, J. 1948. The breeding of self-fertilised crops by crossing Svalof r886-r 946 , 46-71 (Lund).

bateman, A. J. 1951. Controlled plant breeding. Science Progress, 154, 239-252. BOYCE, S. W., COPP, L. G., FRANKEL, O. H. 1947. The effects of selection for yield in wheat. Heredity, $1,223-233$.

CHRISTIAN, C. A., AND GRAY, s. G. 1941. Interplant competition in mixed wheat populations and its relation to single plant selection. Fourn. of C.S.I.R., I4, $59-68$. 
COPELAND, F. C. 1940. Growth rates in inbred and hybrid corn embryos. Collecting Net, ${ }_{5}$, I69.

ENGLEDOW, F. L., AND PAL, B. P. 1934. Investigations on yield in cereals. viIr. Hybrid vigour in wheat. F.A.S., 24, 390-409.

FRANKEL, O. H. I947. The theory of plant breeding for yield. Hered?ty, I, IOg-1 20.

FRANKEL, O. H. I95O. The development and maintenance of superior genetic stocks. Heredity, 4, 89-102.

haldane, J. B. S. I932. The causes of evolution. Longmans, Green and Co.

HARLAN, H. V., AND MARTINI, M. L. I 938 . The effect of natural selection in a mixture of barley varieties. Four. Agr. Res., 57, 189 -199.

HARRINGTON, J. B. I937. The mass pedigree method in the hybridisation improvement of cereals. Four. Amer. Soc. Agron., 29, 379-384.

HARRINGTON, J. B. i 940 . Yielding capacity of wheat crosses as indicated by bulk hybrid tests. Can. Four. Res., I8, 578-584.

hutchinson, J. B., PANSE, v. G., AND GOVANDE, G. K. I938. Studies in Plant breeding technique. IV. The inheritance of Agricultural characters in three interstrain crosses in cotton. Ind. Jour. Agr. Sci., VIII, 757-775.

hUtchinson, J. B., PANSE, v. G., APTE, N. S., AND PUGH, B. M. I938. Studies in plant breeding technique. III. Crop analysis and varietal improvement in malvi jowar. Ind. Four. Sci., VIII, 1 $3^{1-1} 5^{2}$.

IMMER, F. R. I94I. Relation between yielding ability and homozygosis in barley crosses. 7. Amer. Soc. Agron., 33, 200-206.

LAUDE, H. H., AND SWANSON, A. F. 1942. Natural selection in varietal mixtures of winter wheat. Four. Amer. Soc. Agron., 34, 270-274.

MATHER, K. 1942. The balance of polygenic combinations. Four. Gen., 43, 309-336.

MATHER, K. 1949. Biometrical genetics. London: Methuen.

PANSE, V. G. I940. The application of genetics to plant breeding. II. The inheritance of quantitative characters and plant breeding. Four. Gen., $X L, 283-299$.

PANSE, V. G. 1947. Symposium on statistical methods in plant and animal breeding. Proc. Ind. Acad. of Sci., $X X V$.

Sмiтн, н. . . 1936. A discriminant function for plant selection. Ann. of Eugenics, 7, $240-250$.

swanson, c. A. Survival of four barley varieties in a mixture. Agron. Fournal, $4^{I}$, 459-461.

WEISS, M. G., WEBER, C. R., AND KALTON, R. R. 1947. Early generation testing in soybeans. Four. Amer. Soc. Agron., 39, 79 I-8 I I.

WRIGHT, S. 192I. Systems of mating. III. Assortive mating based on somatic resemblance. Genetics, 6, 144-16 1 . 